\title{
Advances in ICME Implementation: Concepts and Practices
}

\author{
TERRY T. WONG ${ }^{1,2}$ \\ 1.-Aerojet Rocketdyne, Los Angeles, CA, USA. 2.—e-mail: terry.wong@rocket.com
}

No doubt many of us have clicked on links showing us the latest viral videos: videos of cats riding robotic vacuum cleaners, of pets playing outside after the latest snow storm, or of a person trying to show off their athletic ability only to fall flat on their back. Videos like these bring many hits to video-sharing websites like YouTube because all of us like to be entertained. Most videos on YouTube are entertainment-related videos. These videos not only bring revenue to the hosting sites but can also make stars out of previously unknown people. In addition to the entertainmentfocused videos, these hosting sites also offer videos that many Do It Yourselfers (DIYers) often turn to first before calling a repairman or a mechanic. These videos will show the DIYers both that the repair can be done and inspire the DIYers to attempt the repair.

Like many weekend DIYers, engineers and scientist also benefit from the example of others. We often need to see how others do it to both know that it can be done and be inspired to find new applications for the same principles. To promote the emerging area of ICME, the ICME technical committee of The Minerals, Metals \& Materials Society chose three articles as examples of the implementation of ICME. Our goal is that these three articles not only document the practice of ICME but also inspire you to find your own application of ICME.

The first two articles use the CALPHAD approach in their ICME implementation to aid in the development of new materials. Based on the fundamental principle that material properties are a function of the microstructure of the material, the first article, "ICME Design of a Castable, Creep-Resistant, Single-Crystal Turbine Alloy," by Jiadong Gong and his colleagues at Questek show how Questek used the microstructural predictive ability associated with the CALPHAD approach to develop tools to help design a new turbine alloy. The example in this article shows how the ICME tools that they developed helped them design a castable, low-Re, creep-resistant, single-crystal, Ni-

Terry T. Wong is the JOM advisor for the ICME Committee of the TMS Materials Processing and Manufacturing Division, and guest editor for the topic Advances in ICME Implementation: Concepts and Practices in this issue. based superalloy. The second article, "High-Throughput Thermodynamic Modeling and Uncertainty Quantification for ICME," by Richard Otis and Zi-Kui Liu from the NASA Jet Propulsion Laboratory and Pennsylvania State University, respectively, aim to show how CALPHAD can be central to the ICME vision by being a starting point in the ICME supply chain. Specifically, what Otis and Liu show is that it is possible to quantify uncertainty computational thermodynamics. This ability to quantify the uncertainty of a CALPHAD model greatly helps in realizing an important aspect of the ICME vision, namely, the uncertainty of a model based on the ICME technique. The third and last article, "Validating a Model for Welding Induced Residual Stress Using High-Energy X-ray Diffraction," by J.C. Mach et al. is a collaborative effort among Caterpillar, Cornell University, and the University of Illinois at Urbana-Champaign. In this article, an ICME model to predict the residual stress in a welded component was validated through x-ray diffraction using synchrotron radiation. The ability to validate an ICME-based residual stress prediction model is indeed a success story because having such a model greatly informs a manufacturer such as Caterpillar to predict the possible life of a component that they manufacture.

The following articles are published under the topic "Advances in ICME Implementation: Concepts and Practices" in the May 2017 issue (vol. 69, no. 5) of JOM and can be accessed via the $J O M$ page at http://link. springer.com/journal/11837/69/5/page/1link.springer. com:

- "ICME Design of a Castable, Creep-Resistant, Single-Crystal Turbine Alloy" by Jiadong Gong, James Saal, Ida Berglound, Jason Sebastian, and Gregory Olson

- "High-Throughput Thermodynamic Modeling and Uncertainty Quantification for ICME" by Richard A. Otis and Zi-Kui Liu

- "Validating a Model for Welding Induced Residual Stress Using High-Energy X-ray Diffraction” by J.C. Mach, C.J. Budrow, D.C. Pagan, J.P.C. Ruff, J.-S. Park, J. Okasinski, A.J. Beaudoin, and M.P. Miller. 